\title{
Structure, morphology and corrosion resistance of Ni-Mo+PTh composite coatings
}

\author{
J NIEDBAŁA* \\ Institute of Non-Ferrous Metals, ul. Sowińskiego 5, Poland
}

MS received 25 July 2014; revised 20 October 2014

\begin{abstract}
Ni-Mo+PTh composite coatings were prepared from nickel-molybdenum galvanic bath with the addition of thiophene ( $\mathrm{Th}$ ) and $\mathrm{HClO}_{4}$ as result of two processes: induced $\mathrm{Ni}-\mathrm{Mo}$ alloy deposition and PTh polymerization. A scanning electron microscope was used for surface morphology characterization of the coatings. The Scanning Electrochemical Workstation M370 was used to the surface map of the tested composite coatings. The chemical composition of the coatings was determined by the energy-dispersive spectroscopy (EDS) method. It was stated that the surface of the coatings are characterized by the presence of Ni-Mo particles and polythiophene agglomerates. Electrochemical corrosion investigations of coatings were carried out in the $5 \mathrm{M} \mathrm{KOH}$ solution, using voltammetry and electrochemical impedance spectroscopy (EIS) methods. On the basis of these research works it was found that the composite Ni-Mo+PTh coatings are more corrosion resistant in alkaline solution than Ni-Mo. The reasons for this are the presence of the polymer on the surface of the coatings and a decrease of corrosion active surface area of the coatings.
\end{abstract}

Keywords. Ni-Mo+PTh composite coatings; electropolymerization; electrodeposition; corrosion resistance.

\section{Introduction}

The polymer built-in into the metallic matrix changed the surface morphology of the layer obtained in the electrolytic process. ${ }^{1-9}$ The developed surface of the electrolytic layer may be smoothened after polymer building (most often in pores). The polymer particles located on the surface can change surface density of the electrons in the metallic matrix. ${ }^{2,5-9}$

The composite coatings containing a metallic matrix and polymers may be produced as a result of (a) cathodic deposition metallic matrix and polymer obtained in cathodic polymerization of monomer, (b) the alternatively deposition metallic matrix on the cathode and electropolymerization and deposition polymer in the anodic process and (c) building polymer particles during matrix deposition. ${ }^{1,3-11}$ They are used for different purposes. ${ }^{10,12-15}$ It was found that the addition of polymers may improve some properties of the obtained coatings, e.g., the nickel coatings exhibited higher microhardness compared with those prepared using pure nickel. ${ }^{1}$

Electrochemical properties of nickel-molybdenum coatings are well known. Their wide application is a result of specific properties, exhibit good corrosion resistance in aggressive solutions and also high catalytic activity for many electrochemical processes. ${ }^{2,16-19}$

\footnotetext{
*Author for correspondence (jolantan@imn.gliwice.pl)
}

Therefore in this study nickel-molybdenum alloys are used as matrix in composite coatings, containing additional polymer component as polythiophene. For determination of the influence the polythiophene in the composite coatings on the corrosion resistance, these coatings were compared with nickel-molybdenum coatings. The purpose of this work was to evaluate the suitability of $\mathrm{Ni}-\mathrm{Mo}+\mathrm{PTh}$ composite coatings as electrode materials in corrosion resistance investigations in an alkaline solution, with respect to their surface morphology and chemical and phase composition.

\section{Experimental}

Electrolytical coatings with polythiophene (PTh) were prepared from a mixture of two solutions: (I) containing (mol $\left.\mathrm{dm}^{-3}\right)^{7,8} \mathrm{Na}_{2} \mathrm{MoO}_{4}$ 0.035; $\mathrm{NiSO}_{4}$ 0.75; $\mathrm{Na}_{3} \mathrm{C}_{6} \mathrm{H}_{5} \mathrm{O}_{7} \quad 0.45$; pH 6.0-7.0 and (II) containing (mol dm$\left.{ }^{-3}\right): \mathrm{HClO}_{4} 0.025$ and thiophene (Th) $\mathrm{C}_{4} \mathrm{H}_{4} \mathrm{~S}$ (99.9\% Aldrich) 0.1. Reagents of analytical purity and twice distilled water were used for the solution. All components of (I) bath were solubilized separately in small volume of distilled water. $\mathrm{Ni}-\mathrm{Mo}+\mathrm{PTh}$ coatings were electrodeposited from a mixture containing solutions (I) and (II) in proportion 3:1. Thiophene was freshly distilled and next solubilized in $\mathrm{HClO}_{4}$.

The coatings on a steel substrate (St3S steel, $4 \mathrm{~cm}^{2}$ plate), preliminarily polished and then etched chemically in $\mathrm{HCl}$ solution ( $\mathrm{v} / \mathrm{v} 1: 1)$ for $5 \mathrm{~min}$ and electrochemically in a $0.8 \mathrm{~mol} \mathrm{dm}^{-3}$ solution of sodium gluconate $\mathrm{C}_{6} \mathrm{H}_{11} \mathrm{NaO}_{7}$. The other side of a plate was covered with non-conducting, chemically resistant adhesive. During deposition process the 
bath was stirred mechanically ( $250 \mathrm{rev} \mathrm{min}^{-1}$ ). Temperature of the bath was $298 \mathrm{~K}$ and $\mathrm{pH}$ was 6-7. The Ni$\mathrm{Mo}+\mathrm{PTh}$ coatings were deposited under galvanostatic conditions at the current densities of $j=100(t=30 \mathrm{~min})$ and $200 \mathrm{~mA} \mathrm{~cm}^{-2}(t=15 \mathrm{~min})$. Comparative tests were carried out for Ni-Mo alloy containing comparable amount of Mo $(21.7 \%)$.

The surface morphology of the coatings was examined using JSM-648 electron microscope, and surface images were recorded at the accelerating voltage of $15 \mathrm{kV}$. The Scanning Electrochemical Workstation M370 was used to the surface map of the tested composite coatings. The scanning Kelvin probe (SKP) is a non-contact, non-destructive instrument designed to measure the surface work function difference between conducting, coated or semi-conducting materials and a metallic probe. The technique operates using a vibrating capacitance probe, and through a swept backing potential, the work function difference is measured between the scanning probe reference tip and sample surface. The work function can be directly correlated to the surface condition. Using the formula: $d_{0}=\left(E_{k}-E\right) \varepsilon S A_{0} \omega \cos (\omega t)-$ $I A_{0} \sin (\omega t)^{2} / I$ the distance between the microelectrode and the scanned surface can be determined. The contents of $\mathrm{Ni}$, Mo and $\mathrm{C}$ in the coatings were determined by the energydispersive spectroscopy (EDS) method.

Electrochemical corrosion resistance investigations were conducted on the coatings in a three-electrode cell, using potentiodynamic and electrochemical impedance spectroscopy (EIS) methods. These measurements were carried out in a $5 \mathrm{M} \mathrm{KOH}$ solution, using an Autolab ${ }^{\circledR / P G S T S T 20}$ (Eco Chemie B.V., the Netherlands) electrochemical system. Geometric surface area of all electrodes was $1 \mathrm{~cm}^{2}$. The auxiliary electrode was a platinum mesh and the reference electrode was of the type $\mathrm{Hg} / \mathrm{HgO} / 6 \mathrm{M} \mathrm{KOH}$. Open circuit potentials of the coatings were determined using a range of $\pm 0.150 \mathrm{~V}$ from the determined value and the recorded potentiodynamic curve with rate $v=0.050 \mathrm{~V} \mathrm{~min}^{-1}$. Values of the corrosion potentials and the corrosion currents were determined by the Stern method. The electrochemical impedance measurements were performed at the corrosion potential.
In these measurements the amplitude of the ac signal was $0.005 \mathrm{~V}$. A frequency range from $10 \mathrm{kHz}$ to $0.1 \mathrm{~Hz}$ was covered with 10 points per decade. All electrochemical investigations were made at $293 \mathrm{~K}$.

\section{Results and discussion}

The Ni-Mo+PTh coatings show good adhesion to the substrate and no internal stresses causing their defoliation are observed. The Ni-Mo+PTh coatings are characterized by dark-grey, graphite colour. The surface is mat like and porous. It was found that the structure of the $\mathrm{Ni}-\mathrm{Mo}$ coatings is relatively regular with the island character ${ }^{5-7}$ (figure 1a). In Ni-Mo+PTh coatings the polymer particles are uniformly embedded into the Ni-Mo matrix and built into the composite matrix ${ }^{7,8}$ (figure $1 \mathrm{~b}$ ). It may be assumed that the nickel-molybdenum inductive electrodepositing process and the electropolymerization/electrodeposition process of polymer proceeds parallel and independently. Polymer embedded into the Ni-Mo matrix changes the structure. The results show that the deposition process of Ni-Mo is different near the deposited polymer. With the grain size of the alloy can be assumed that the process of formation of Ni-Mo occurs more easily in the vicinity of the polymer. In these areas, near the polythiophene, the Ni-Mo grains are greater (figure 1b).

On the surface maps $\mathrm{Ni}-\mathrm{Mo}+\mathrm{PTh}$ and $\mathrm{Ni}-\mathrm{Mo}$ coatings was clearly visible differences between character the surface coating with built-in polymer and surface alloy coatings (figure 2). Alloy coatings are less developed and have greater regularity in comparison with the composite coatings with PTh (figure 2a). The thickness of Ni-Mo coatings ranges between 30 and $60 \mu \mathrm{m}$.

Surface of the composite coatings with polymer has a much more developed and porous character. However, comparing the obtained maps with surface morphology, should be noted, that on the maps was confirmed lack of cracks and faults on the surface (figure 2b). The thickness of $\mathrm{Ni}-\mathrm{Mo}+\mathrm{PTh}$ coatings varies between 70 and $120 \mu \mathrm{m}$.
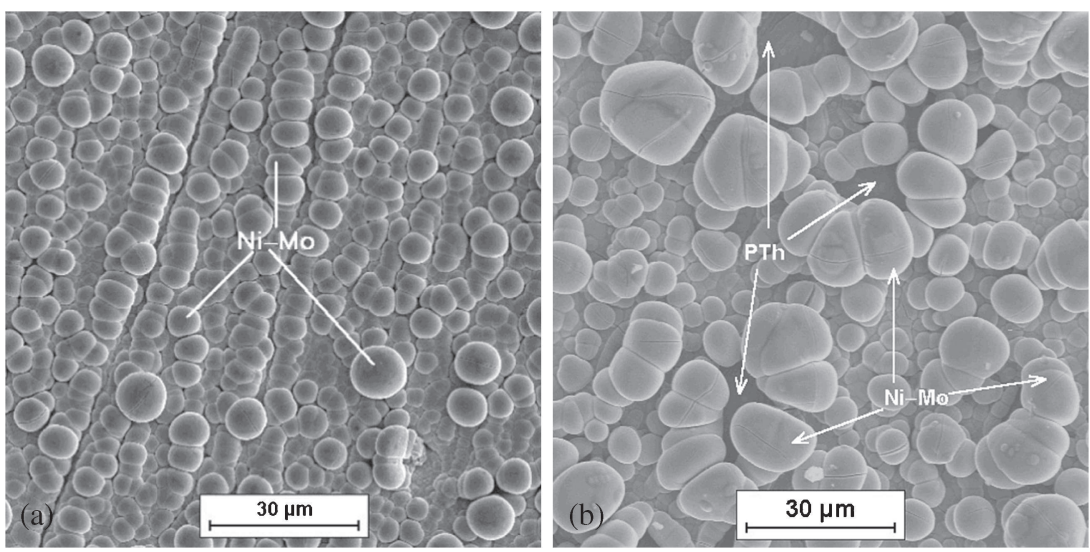

Figure 1. Surface morphology of (a) $\mathrm{Ni}-\mathrm{Mo}^{5-7}$ and (b) Ni-Mo+PTh. ${ }^{7,8}$ 

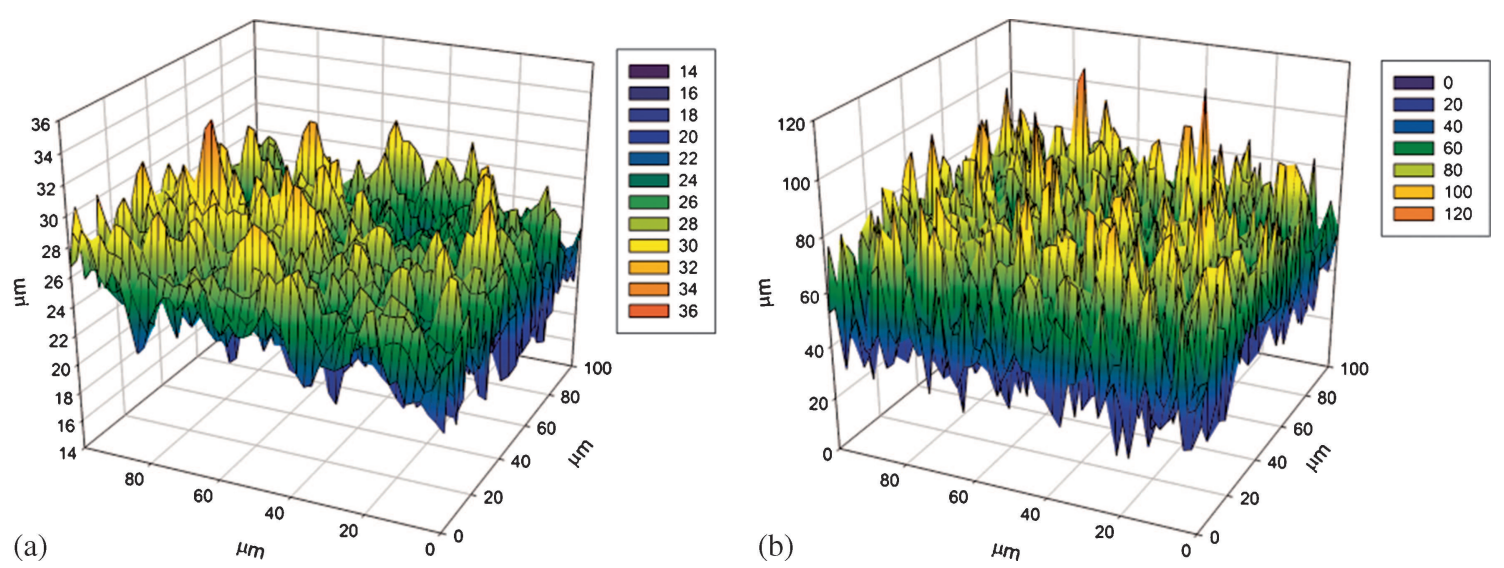

Figure 2. Surface map of the Scanning Kelvin Probe signal recorded for (a) Ni-Mo and (b) Ni-Mo+PTh composite coatings.

Table 1. Chemical composition and corrosion parameters of the $\mathrm{Ni}-\mathrm{Mo}$ and $\mathrm{Ni}-\mathrm{Mo}+\mathrm{PTh}$ coatings.

\begin{tabular}{|c|c|c|c|c|c|c|c|c|c|}
\hline Type of coatings & $\mathrm{Ni}(\%)$ & $\operatorname{Mo~}(\%)$ & $\mathrm{C}(\%)$ & $\mathrm{S}(\%)$ & PTh ca. (\%) & $j_{\text {cor }}\left(\mu \mathrm{A} \mathrm{cm}^{-2}\right)$ & $E_{\mathrm{cor}} / \mathrm{V}$ & $R_{\mathrm{p}}\left(\mathrm{k} \Omega \mathrm{cm}^{2}\right)$ & $\begin{array}{l}\text { Corrosion rate } \\
\text { (mm per year) }\end{array}$ \\
\hline Ni-Mo & $78.3 \pm 0.9$ & $21.7 \pm 0.9$ & - & - & - & 0.678 & -0.780 & 8.6 & 0.056 \\
\hline $\mathrm{Ni}-\mathrm{Mo}+\mathrm{PTh} 100$ & $75.1 \pm 1.8$ & $20.2 \pm 0.7$ & $2.8 \pm 0.9$ & $1.9 \pm 0.9$ & 4.9 & 0.198 & -0.393 & 18.8 & 0.037 \\
\hline Ni-Mo+PTh200 & $68.3 \pm 2.0$ & $23.5 \pm 0.7$ & $4.9 \pm 1.3$ & $3.3 \pm 1.1$ & 8.6 & 0.145 & -0.478 & 19.7 & 0.022 \\
\hline
\end{tabular}

The chemical analysis of the Ni-Mo+PTh coatings was determined by the EDS method (table 1). They showed that for $\mathrm{Ni}-\mathrm{Mo}+\mathrm{PTh} 100$ the content of the carbon was $2.8 \%$ and for the Ni-Mo+PTh200 was almost 2.1 higher $(4.9 \%)$. It was found that analogical dependence was for sulphur content in the coatings- $-\mathrm{Ni}-\mathrm{Mo}+\mathrm{PTh} 1001.9 \% \mathrm{~S}, \mathrm{Ni}-$ Mo+PTh200 3.3\%S (table 1). On the basis of the C and S content in the coatings were made calculations of the polythiophene content in Ni-Mo+PTh coatings. They showed that it ranged about $4.9 \%$ for $\mathrm{Ni}-\mathrm{Mo}+\mathrm{PTh} 100$ and $8.6 \%$ for $\mathrm{Ni}-\mathrm{Mo}+\mathrm{PTh} 200$ the nickel content in the coatings decrease, whereas molybdenum content insignificant increase with the increase in the deposition current density $j$ (table 1 ).

Values of the corrosion parameters were determined from measured dependencies of the $j=f(E)$ behaviour. It was found that for the composite coatings with polythiophene the value of the corrosion current is lower and the value of the corrosion potential is more positive compared with the corresponding values of the Ni-Mo coatings (figure 3 and table 1). This suggests greater resistance of the $\mathrm{Ni}-\mathrm{Mo}+\mathrm{PTh}$ coatings in alkaline solutions. The results of corrosion tests show that the lowest corrosion rate $(0.022 \mathrm{~mm}$ per year) exhibit Ni-Mo+8.6\% PTh coatings (table 1). This value is lower than corrosion rate in case of composite coating with a lower content of polythiophene and Ni-Mo alloy. The corrosion current density for this coating is equal $-0.145 \mu \mathrm{A}$ $\mathrm{cm}^{-2}$ (figure 3 , curve 1 and table 1), so this layer could be recommended as protection cover. Corrosion potential of $\mathrm{Ni}-\mathrm{Mo}+\mathrm{PTh}$ coatings, with increase contents of polythiophene changes from -0.393 to $-0.478 \mathrm{~V}$ (figure 3 ). Value of

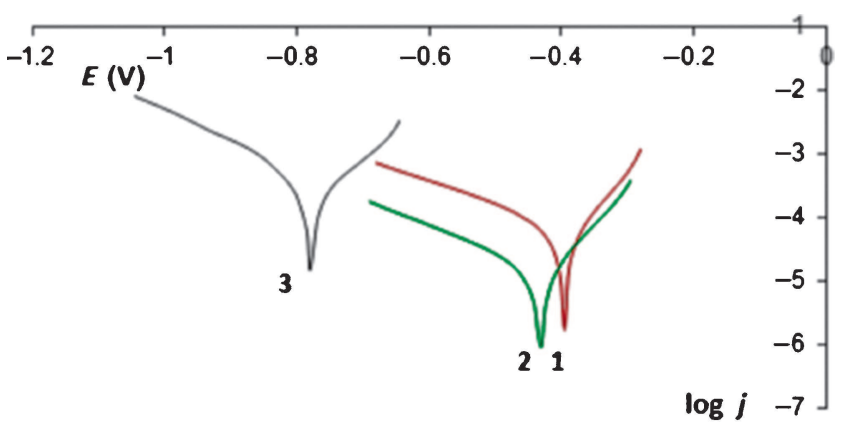

Figure 3. Dependences of $\log j=f(E)$ for the (1) $\mathrm{Ni}-\mathrm{Mo}+8.6 \%$ $\mathrm{PTh},(2) \mathrm{Mo}+4.9 \% \mathrm{PTh}$ and (3) $\mathrm{Ni}-21.7 \% \mathrm{Mo}$.

potential Ni-Mo coatings containing comparable content of Mo is equal $-0.780 \mathrm{~V}$ (figure 3 ). Increase of polythiophene contents in coatings, causes decrease of corrosion current (table 1).

Result of this change of corrosion current is increase of polarization resistance from 18.8 to $19.7 \mathrm{k} \Omega \mathrm{cm}^{2}$ for $\mathrm{Ni}$ $\mathrm{Mo}+8.6 \% \mathrm{PTh}$. The polarization resistance for $\mathrm{Ni}-\mathrm{Mo}$ coatings was less from investigation coatings $\left(8.6 \mathrm{k} \Omega \mathrm{cm}^{2}\right)$. Although the value of potential corrosion was more positive for coatings with less content of polythiophene, the others corrosion parameters (corrosion current and polarization resistance) show the better corrosion resistance for $\mathrm{Ni}-\mathrm{Mo}+8.6 \%$ PTh coatings (table 1).

The results of the EIS investigations were analysed in the form Nyquist $\left(Z^{\prime \prime}=f\left(Z^{\prime}\right)\right.$ ) (figure $4 \mathrm{a}-\mathrm{c}$ ) and Bode (log $|Z|=f(\log \omega))$ and $\phi=f(\log \omega)$ diagrams (figure 5a and b), where $|Z|=\left(\left(Z^{\prime}\right)^{2}+\left(Z^{\prime \prime}\right)^{2}\right)^{1 / 2}$ and $\phi=$ arctangent 

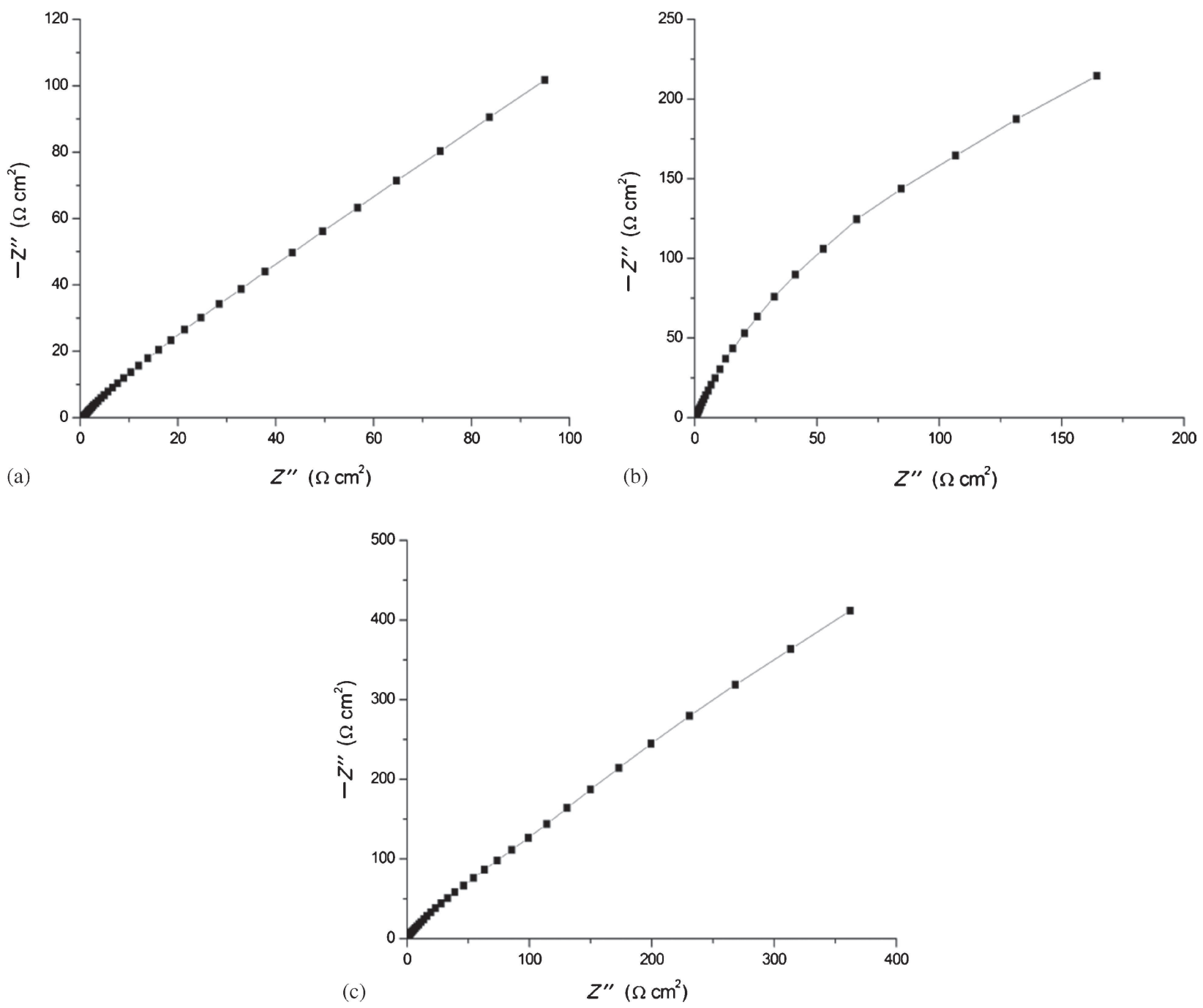

Figure 4. Dependences of $Z^{\prime \prime}=f\left(Z^{\prime}\right)$ for the (a) Ni-21.7\%Mo, (b) Ni-Mo+4.9\%PTh and (c) Ni-Mo+8.6\%PTh coatings.


Figure 5. Dependences of $\log \mid \mathrm{ZI}=f(\log w)$ for $(\mathbf{a}) \mathrm{Ni}-21.7 \% \mathrm{Mo}(-), \mathrm{Ni}-\mathrm{Mo}+4.9 \% \mathrm{PTh}(\square), \mathrm{Ni}-\mathrm{Mo}+8.6 \% \mathrm{PTh}(\boldsymbol{\square})$ and $f=$ $f(\log w)(\mathbf{b})$ for $\mathrm{Ni}-21.7 \% \mathrm{Mo}(-), \mathrm{Ni}-\mathrm{Mo}+4.9 \% \mathrm{PTh}(\square), \mathrm{Ni}-\mathrm{Mo}+8.6 \% \mathrm{PTh}(\mathbf{\square})$. 
Table 2. Corrosion parameters of Ni-Mo and $\mathrm{Ni}-\mathrm{Mo}+\mathrm{PTh}$ coatings, calculated from EIS method.

\begin{tabular}{lccc}
\hline Type of coatings & $C_{\mathrm{dl}}\left(\mu \mathrm{F} \mathrm{cm}^{-2}\right)$ & $R_{\mathrm{f}}$ & $R_{\mathrm{ct}}\left(\Omega \mathrm{cm}^{2}\right)$ \\
\hline Ni-21.7\%Mo & $3.9 \times 10^{-4}$ & 19.5 & 335.2 \\
Ni-20.2\%Mo+4.9\%PTh & $1.44 \times 10^{-4}$ & 7.2 & 528.6 \\
Ni-23.5\%Mo+8.6\%PTh & $0.99 \times 10^{-4}$ & 4.95 & 757.6 \\
\hline
\end{tabular}

$\left(Z^{\prime \prime} / Z^{\prime}\right)$. These investigations confirmed the diversified characteristics of the impedance components (real $Z^{\prime}$ and imaginary $Z^{\prime \prime}$ ) in the alkaline solution. The Nyquist diagram for the $\mathrm{Ni}-21.7 \% \mathrm{Mo}, \mathrm{Ni}-20.2 \% \mathrm{Mo}+4.9 \% \mathrm{PTh}$ and $\mathrm{Ni}-$ $23.5 \% \mathrm{Mo}+8.6 \% \mathrm{PTh}$ composite coatings is characterized by a straight line in the whole range of frequencies (suggesting a diffusion mechanism for the corrosion process) (figure $4 \mathrm{a}-\mathrm{c}$ ). It was found that the coatings with $8.6 \%$ PTh (figure 4c) are characterized by higher value of the impedance module and phase angle compared with those for the $\mathrm{Ni}-\mathrm{Mo}+4.9 \% \mathrm{PTh}$ and $\mathrm{Ni}-21.7 \% \mathrm{Mo}$ coatings (figure $4 \mathrm{a}$ and b). Moreover, the dependence $\phi=f(\log \omega)$ for the coatings with $8.6 \%$ PTh (figure $5 \mathrm{~b}$ ) shows a wider range of independence of the phase angle value from the logarithm of angular frequency compared with the $\mathrm{Ni}-\mathrm{Mo}+4.9 \% \mathrm{PTh}$ and $\mathrm{Ni}-\mathrm{Mo}$ coatings (figure $5 \mathrm{a}$ ). This wider range of independence of $\phi=f(\log \omega)$, implies that the coating is more corrosion resistant (figure 5).

For the examined coatings impedance Nyquist diagram (figure $4 \mathrm{a}-\mathrm{c}$ ), a semicircle at the high frequencies and linear dependence of impedance components (real $Z^{\prime}$ and imaginary $Z^{\prime \prime}$ ) at the low frequencies are characterized. Nyquist diagram shows activation control at the high frequencies point, however at the low frequencies point at diffusion control of corrosion process. It was found that for this dependence of impedance components $\left(Z^{\prime}\right.$ and $\left.Z^{\prime \prime}\right)$ at particular frequencies, value of charge-transfer resistance is not possible to determine, as described in other papers.

The Bode dependences also confirm better corrosion resistance for examined coatings with and without polythiophene (figure $5 \mathrm{a}$ and $\mathrm{b}$ ). Proof of this is the value of doublelayer capacitance $C_{\mathrm{dl}}$ (table 2). Proportion of the value of capacitance $C_{\mathrm{dl}}$ to capacitance of ideal smooth surface of electrolytic nickel $\left(30 \mu \mathrm{F} \mathrm{cm}{ }^{-2}\right)$ gives a value of factor of electrochemical active surface $R_{\mathrm{f}}$ in the corrosion process. Little values of $R_{\mathrm{f}}$, point at blocking of corrosion processes, great value of $R_{\mathrm{f}}$, point at activation of corrosion processes on greater surface. The results of the analysis of $R_{\mathrm{f}}$ factors show that for the $\mathrm{Ni}-\mathrm{Mo}+8.6 \%$ PTh coating blocking of corrosion processes is compared to other investigation coatings. The proof of this is greater value of charge-transfer resistance $R_{\mathrm{ct}}$ for this coating (table 2).

On the basis of these electrochemical investigations it was found that the coatings with $8.6 \%$ polythiophene are more corrosion resistant in alkaline solution than the $4.9 \% \mathrm{PTh}$ and $\mathrm{Ni}-21.7 \%$ Mo coatings. Probably it is a result of the corrosion reaction, which at-first proceeded in polymer grains presented in $\mathrm{Ni}-\mathrm{Mo}+\mathrm{PTh}$ composite coatings, because in polythiophene proceed oxidizing-reduction processes. It limited corrosion in the composite Ni-Mo matrix.

\section{Conclusion}

It was found that $\mathrm{Ni}-\mathrm{Mo}+\mathrm{PTh}$ coatings are more resistant to corrosion in alkaline solutions than the Ni-21.7\% Mo coating. The coatings with $8.6 \%$ polythiophene show a more positive value of the corrosion potential, a lower value of the corrosion current and also higher value of the polarization resistance than Ni-Mo coating. This is caused by the presence of PTh, which decreased active surface corrosion area. In polythiophene proceed oxidizing-reduction processes and these limited corrosion reaction in alloy matrix. Moreover, parameters determined by the EIS method provide a means for estimating the corrosion resistance of coatings, and confirm the results obtained from potentiodynamic measurements.

\section{References}

1. Hamid Z A and Ghayad J M 2002 Mater. Lett. 53238

2. Karolus M, Niedbała J, Rówiński E, Łągiewka E and Budniok A 2006 J. Achiev. Mater. Manufact. Eng. 1625

3. Niedbała J, Budniok A and Łagiewka E 2006 Mater. Sci. Forum 514-516 1176

4. Niedbała J, Budniok A and Łągiewka E 2007 Inż. Mater. (Mater. Eng.) 15521

5. Niedbała J, Budniok A and Łagiewka E 2008 Thin Solid Films $\mathbf{5 1 6} 6191$

6. Niedbała J 2008 Using carbon nanomaterials in clean-energy hydrogen systems, Series: NATO science for peace and security series, Subseries: NATO Science for Peace and Security Series C: Environmental Security, XXXIV, Hardcover, Springer ISBN: 978-1-4020-8896-4

7. Niedbała J 2009 Mater. Chem. Phys. 11846

8. Niedbała J 2011 Bull. Mater. Sci. 34993

9. Rówiński E, Karolus M and Łągiewka E 2007 Solid State Phenom. 130245

10. Lindfors T, Bobacka J, Lewen Stam A and Ivaska A 1998 Electrochim. Acta 433503

11. Karolus M, Rówiński E and Łągiewka E 2006 J. Achiev. Mater. Manuf. Eng. 18119

12. Fenelon A M and Breslin C B 2002 Electrochim. Acta 474467

13. Kuwabata S, Masui S, Tomiyori H and Yoneyama H 2000 Electrochim. Acta 4691

14. Levi M D, Gofer Y and Aurbach D 2002 Polym. Adv. Technol. 13697

15. Rajagopalan R and Iroh J O 2002 Surf. Eng. 1859

16. Birry L and Lasia A 2004 J. Appl. Electrochem. 34735

17. Jakšic J M, Vojnovic M V and Krstajic N V 2000 Electrochim. Acta 454151

18. Niedbała J, Popczyk M, Budniok A and Łagiewka E 2004 KSCS 2004 mechanisms of corrosion and corrosion prevention (Helsinki University of Technology) p 195

19. Niedbała J 2006 Mater. Sci. Forum 514-516 465 